\title{
LOS CAMINOS A FILIPINAS
}

\section{ROADS TO PHILIPPINES}

\section{AUTOR}

\section{Pedro Brufao García}

Articulista en varias revistas y publicaciones científicas y de divulgación (España).

pedrobrufalo@hotmail.com

\section{RESUMEN}

Las expediciones a las Filipinas siempre han estado llenas de obstáculos, no obstante las flotas españolas siempre han sabido cómo llegar a través de los años. En 1564 se decide que Miguel López de Legazpi se hiciera cargo de la flota que se dirigiría a las "islas de poniente" para su descubrimiento y desde entonces, España ejerció su influencia en las Filipinas hasta 1898, cuando esta colonia consiguió su independencia.

\section{PALABRAS CLAVE}

Expediciones - Filipinas - Legazpi

\section{ABSTRACT}

Expeditions to the Philippines have always been full of obstacles, however the Spanish fleets have always known how to get through the years. In 1564 it was decided that Miguel Lopez de Legazpi took charge of the fleet that would address the "islands of the west" for their discovery, and since then, Spain was influential in the Philippines until 1898, when the colony gained its independence.

\section{KEY WORDS}

Expeditions-Philippines- Legazpi 


\section{ÍNDICE}

1. Introducción.

2. Filipinas.

\section{Introducción}

Si el Camino de Santiago sirvió en la Edad Media para crear una conciencia de la cultura europea y cristiana, el camino a Filipinas abrió los horizontes culturales a nivel universal, al fin la tierra era redonda en lo económico y en lo cultural.

Dos inmensos mares, el océano Atlántico y el océano Pacífico fueron las primeras autopistas de la información que funcionaron perfectamente, aunque se hayan visto complementadas con las actuales autopistas de la información electrónico-digital. Los pedidos y las ofertas se harán por la fibra óptica o vía satélite pero las mercancías seguirán moviéndose por vía marítima mientras que la Tierra sea tierra y mar.

Filipinas y sus mares fueron el referente que las grandes potencias de los tres siglos anteriores fijaban en sus cimas de acción internacional para mantener su hegemonía. Sin las bases de apoyo a la navegación en las latitudes era imposible mantenerse en el comercio y en los avances de la ciencia de vanguardia.

Entre Europa y Asia había un formidable obstáculo a la navegación, el Continente Americana, hasta que las naciones de este continente se dieron cuenta que eran el gran control del peaje entre la autopista del Atlántico y del Pacífico, y así con esta conciencia, jugando sabiamente su privilegiada situación geoestratégica los Estados Unidos del Norte de América se convirtieron en la gran potencia que son hoy. 
Desde los territorios de Nueva España se comenzó a pensar en las posibilidades que ofrecería el descubrir y conquistar tierras hacia el llamado Mar del Sur y los Mares Australes.

Después de algunos intentos fallidos Felipe II autorizó la salida de una nueva expedición en el año 1564, que sin contravenir los acuerdos internacionales con Portugal, llegaron a Filipinas para crear asentamientos (bares) que favoreciesen el gran comercio de la especería, sobre la ruta abierta por Magallanes y sobre todo encontrar un tornaviaje seguro a Nueva España.

Como menos el hombre sigue incansablemente queriendo navegar hacia el poniente del sol, como siguiendo el camino que el astro rey marca sobre el mar y le cuesta mucho navegar en sentido contrario.

Después de muchos preparativos y discusiones se decide el Primero de Septiembre de 1564 que Miguel López de Legazpi, gobernador y general, nombrado por su majestad, salga para el descubrimiento de las "islas de poniente".

Para cumplir esta orden zarpa de Mechuacán con una flota de cuatro naves, con gentes de mar y tierra, y lo más importante con artesanía y mercadería que unirían cultural y económicamente las dos riberas del Pacífico.

Por el espíritu de la época también embarcaron un grupo de religiosos agustinos, teniendo las dotaciones que acatar y respetar la religión católica.

Se marcó la derrota inicial con escalar en las islas Nublada y Roca Partida en el archipiélago de Revillagigedo, posteriormente, a las islas de los Reyes, Canales y Filipinas. 
Las instrucciones que llevaban eran muy concretas en cuanto a relaciones comerciales, información sobre los portugueses y compromiso estricto de "guardar secreto" de todo cuanto vieran e hicieran.

Los cuatro navíos de nueva construcción se hicieron en el Puerto de la Navidad (Costa Occidental de Nueva España). Los cuatro navíos se podrían catalogar como pataches o galoncetes, siendo sus nombres San Pedro (Nao Capitana), San Pablo (Almirante), San Juan de Letrán y San Lucas.

Las dos primeras eran de unas quinientas toneladas y las segundas de menos de cien toneladas.

Legazpi estaba orgulloso de esta flota y dijo que "eran las mejores piezas que han caído sobre la Mar del Sur y más fuertes y bien aparejadas".

La cabeza científica y verdadero cosmógrafo de la expedición era el Padre de la Orden de San Agustín, Fray Andrés de Urdaneta y los Pilotos expertos en navegación eran gentes procedentes sobre todo de los gremios marineros de Huelva. En total marcharon 150 hombres de mar y otros 200 de armas, amén de los seis religiosos agustinos.

Cuando el noble Miguel López de Legazpi, se hace cargo del mando de la flota, tiene cincuenta años y llevaba más de veintinueve residiendo en Nueva España, tenía nueve hijos dándose el caso que dos de sus nietos le acompañaron en la expedición, siendo uno de ellos J efe de su guardia personal con sólo 16 años.

Las características personales de Legazpi, por las que fue nombrado para esta importante y delicada misión, era la de ser de carácter noble, honrado, cristiano, bondadoso y la de llevarse bien con Fray Hrdamta "que es el que ha de gobernar $y$ guiar la jornada". 
Pues bien después de Ochenta y cinco días de navegación, recaló el 13 de febrero de 1565 en la fachada oriental de las Filipinas, tocando sucesivamente las islas de Samar, Leyte, Limarawa, Camifuin, Bohol, Mindanao, Siquifor, Negros y Lebú, donde funda la villa de San Miguel y continúa hacia Panay, Marbate, Mindoro, Luzón y otras islas menores.

Seis años más tarde funda Manila (junio de 1571) y muere un año después, repentinamente de una afección cardiaca, era el 20 de agosto de 1572.

Legazpi, fue llorando en la Manila que trazara Juan de Herrera desde España, porque supo ejercer ampliamente la tolerancia, la concordia, la justicia, el desinterés y sobre todo el respeto a los demás.

Es importante recordar que las navegaciones en alta mar en el siglo XVI sólo tenían exactitud en el dato de la latitud apreciada por la observación del sol a medio día, que el cálculo de la longitud era muy impreciso y que las desviaciones de la aguja magnética influían notablemente en las derrotas seguidas a rumbo de bengala.

A estas dificultades había que añadir el escrupuloso respeto al Tratado de Tordesillas que delimitaba las zonas de acción de España y Portugal, cosa que se obvió al abrir las instrucciones secretas una vez recorridas las primeras cien millas, que ordenaban el rumbo directo a las islas Filipinas.

A partir de este momento, por llevar ya muchos días de navegación las dudas e incertidumbres aumentan naturalmente por las flaquezas humanas que aumentan cuando la permanencia en la mar es muy prolongada, por lo que los hombres de las dotaciones necesitan el carácter fuerte de un Almirante que los mantenga y anime para llevar a buen fin la misión ordenada. 
Por las grandes variaciones de la aguja magnética tenían que hacer grandes correcciones sobre el rumbo marcado certeramente por la estrella Polar, por lo que los días de navegación aumentaban sobre los cálculos hechos inicialmente, con todos los problemas que trae consigo de escasez extrema en víveres y sobre todo de agua dulce, añadiendo nervios y penalidades a los naturalmente previstos.

Como en todas las navegaciones de la época, la navegación se basaba en la constancia y acierto del estudio de los vientos alisios, en favor y aprovechamiento de los mismos se construían las naves y su elemento propulsor las velas, diseñadas para navegar a un largo con lo que se conseguí hacer singladuras de treinta leguas. Cuando por fin consiguen ver las primeras tierras, el 9 de enero de 1565, han pasado cincuenta larguísimos días, se acercan a sus costas y no pueden dar el ancla por los profundos fondos que circundan estas islas de los Barbudos.

Se puede decir que esta etapa estuvo bien controlado en cuanto a la navegación se refiere porque el camino ya se había recorrido en expediciones anteriores, los cálculos de la derrota fueron correctos y la estimación de las distancias navegadas no fueron excesivamente erróneas aunque sufrieron las alteraciones de la corriente material que en esta zona supone a penas un nudo (1854 m/hora), y los vientos alisios fueron propicios, con pocas calmas y ninguna tormenta. Esta isla de los Barbudos es la actual Megit, de la cadena de las Ratak, en el archipiélago de las Marshall.

Se detuvieron apenas unas horas por lo peligroso del fondeadero, y siguiendo el mismo rumbo descubrieron otras islas de poca extensión en forma de atolón que llamaron sucesivamente de los Placeres, San Pablo y San Pedro, en un mismo rumbo debieron pasar cerca de otras islas que no vieron, quizás por navegar de noche en esas horas. 
El día trece sufren el primer temporal serio con vientos del noroeste con más fuerza, que les obligó a recoger algo las velas y dar las pequeñas de copa o tormentines, en aquella época esta forma de navegar se llamaba a "papahigos".

Sobre el quince de Enero, los pilotos habrán estimado que estarían llegando a las Filipinas por esto y por aprovechar un buen viento de levante que les daba un andar de 40 leguas por día, despreciaron el avistamiento de otras islas.

Ante los criterios opuestos de los pilotos sobre la situación real, Legazpi los reunió en la Capitana el 17 de enero de 1565 y esta reunión consensuó navegar sobre el paralelo de los trece grados y en franquía hacia el resto en demanda de las islas Filipinas. Así lo hacen y navegan desde el día 17 al 22 con rumbo noroeste y después al oeste.

El mismo día 22 se les acercaron unas embarcaciones aparejadas con vela latina que procedían de la inmediata Isla de Guam del archipiélago de los Ladrones (hoy Marianas).

Entre el día 23 y 24 cargaron agua y víveres, pero por precaución nadie desembarcó, en estas faenas permanecieron hasta el 3 de febrero y allí dejó la vida un soldado víctima de una refriega.

Se deliberó sobre la conveniencia de establecer un apostadero en ésta isla y se prosiguió la navegación que francamente irrumpía en la zona adjudicada en arbitraje papal a los portugueses.

Por fin el día 11 domingo, fondean a las siete de la tarde en la bahía de Zibaban en la isla de Tandeya del archipiélago filipino, habrán navegado 2.300 leguas en setenta y cuatro larguísimos días. 
Este trece de Enero del siglo XVI, los buques de España están entrando por la puerta del Este la Isla de Samar al archipiélago de las Islas Filipinas (Tandaya, según la llamaron ellos).

\section{Filipinas.}

Como todos los descubrimientos españoles se hizo por la mar, con mucha técnica, esfuerzo y fe en la empresa acometida.

- 1521.- Las descubre Magallanes. Muere en la isla de Mactán en apoyo del Rey de Cebú y llamó al archipiélago San Lázaro, por el santo del día.

- 1525.- Rey López de Villalobos las denominó Filipinas.

- 1565-1571.- Legazpi, conquista y funda Manila. Son unas 8.000 islas. Primera "conexión regular marítima" a través de Nueva España (México) - Maos de Acapulco.

Porque la navegación por el Cabo de Buena Esperanza estaba vedada a los españoles por lo convenido con los "portugueses".

- 1572.- Atacados por los chinos.

- 1580.- Atacados por los japoneses.

- 1606-1619-1624-1646.- Ataques de los Holandeses a Filipinas y Moluscas del Imperio del Rey de España que también lo es de Portugal más de 30 navíos de Holanda dedicados a atacar: Filipinas, Moluscas, Macao y Formosa.

- 1745.- Un nuevo ataque chino.

- 1762.- Los ingleses se apoderan de Manila. El arzobispo era el Capitán General. Atacan con 16 navíos y 7000 hombres de desembarco. La casa de Durtún pensó en DEJAR las Filipinas por el mucho gasto y casi nula aportación.

Misioneros.

La Marina se establece en Filipinas en un Apostadero que realizó el Almirante Ignacio María de Álava que llegó en un viaje de circunnavegación que duró 


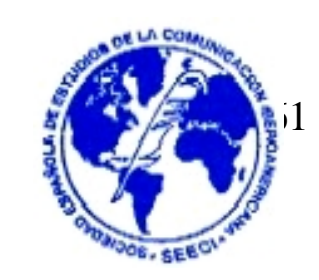

siete años, tres meses $y$ dos días. Con anterioridad, desde 1775 existía en las islas una "Marina Corsaria", dependiente directamente del Gobernador General. Estos eran los herederos de la de los Pintados, llamados así los bisayas por sus tatuajes. Persistieron los de "La Corsaria" y se dispuso en 1813 que no hubiese allí otra Marina que la de la Armada y las de la "Corsaria" integrarse como fuerzas utiles.

En 1843 el Apostadero no "dependía" directamente del Capitán General excepto en el natural orden jurisdiccional con la doble dependencia de la metrópoli y de Manila. La Armada desarrolla una actividad incansable por aquellos intrincados y peligrosos mares, en beneficio de los intereses de España.

La flota de Filipinas se agrupó lógicamente en buques de transporte y unas Fuerzas sutiles con buques y lanchones de poco calado para penetrar en los estrechos y en las profundas rías.

A caballo de 1850 comienza la sustitución de la vela por la máquina de vapor, pasando por unos buques de propulsión mixta que prestaron excelentes servicios aunque las incomodidades a bordo seguían siendo las mismas que en siglos anteriores.

Hoy la potencia de propulsión de estos buques causaría risa ya que no pasaban de los 40 o 50 caballos la fuerza de estas máquinas, que movían enormes hélices de grandes palas y pocas revoluciones.

La mayor expedición naval estuvo compuesta por "la" fragata, tres corbetas, dos goletas, dos transportes de guerra, un bergantín goleta y doce cañoneros y doce buques mercantes con tropas. El Almirante Pezuela enarboló su insignia en la fragata 
Carmen. Estas expediciones se fueron sucediendo entre 1874 y 1890 especialmente en la zona de Mindanao siendo la última la mandada por el General Ramón Blanco.

Aún en 1885 había dificultades en el reconocimiento de la soberanía de algunas islas, apetecidas por Alemania (la Isla de Yap). Entre rebeliones, expediciones y pirateos de los oficiales y soldados de España se iba dejando la vida en aquellas queridas tierras, que dejaron de estar bajo nuestra bandera el 1 de mayo de 1898. No quiero terminar sin rendir tributo a los indígenas filipinos que vivieron en nuestras unidades y a un adversario valiente y con gran pericia marinera y de combate. 